\title{
An innovative approach for detection of, hydrometeor returns from the GU Portable Atmospheric Lidar profiles
}

\author{
B. Choudhury ${ }^{1}$, A. Medhi ${ }^{1}$ and S. Das ${ }^{2}$ \\ ${ }^{1}$ Department of Physics, Gauhati University, Guwahati-781014 \\ ${ }^{2}$ Department of Computer Science, Gauhati University, Guwahati-781014 \\ *bandita.choudhury8@gmail.com
}

\begin{abstract}
Records of backscatter (bs) count and extinction coefficient $(\sigma / \mathrm{km})$ from Potable Atmospheric Lidar (PAL) of Gauhati University $\left(26.15^{\circ} \mathrm{N}, 91.66^{\circ} \mathrm{E}\right)$ are analyzed in an attempt for detection of presence of hydrometeors through identification of type of clouds with special reference to precipitating and non-precipitating characters. For this purposecand bs profiles of aerosol and cloud are examined covering both dry and wet seasons from two years of Lidar data and a parameter called "Roll off Rate (RoR)" from profiles are used as a pointer on presence of hydrometeors in the environment. The paper also presents the application of RoR in estimation of rain rate. The reliability of the approach is examined by comparing the results obtained from the adopted approach with the rain data obtained from rain-gauge and satellite.
\end{abstract}

Key words: Potable Atmospheric Lidar (PAL); Aerosol; Backscatter Counts; Extinction Coefficient; Roll off Rate.

\section{Introduction}

The atmospheric aerosols provide the necessary nuclei for cloud formation (CNN) and so have a direct impact on cloud microphysics and hence precipitation [Stokes et al., 1994; Campbell et al., 2002]. In recent years, versatile ground-based, airborne and space-borne experiments [Devara, 1987; McCormick, 1993] have been developed for better understanding of the aerosol-cloud-precipitation interaction mechanisms. Lidar is one such technique that can be used for analyzing extinction and backscatter count 
(bs) of aerosol and cloud with high spatial-temporal resolution [Spinhirne, 1993; Campbell et al., 2002]. For this purpose, system like Micropulse Lidar (MPL), Bistatic Argon Ion Lidar, MST Radar, Rayleigh Lidar are used extensively [Jayaraman, 1995; Devara, 2002; Baishya et al., 2003; Kumar, 2010]. Amongst the different types of Lidar, the use of MPL in this field of work is very useful. The first Micro Pulse Lidar (MPL) system was designed and tested in the early 1990's by Spinhirne [Spinhirne, 1993]. It is an eye safe instrument for profiling of optical properties such as backscatter $(\beta / \mathrm{km})$ and extinction coefficients $(\sigma / \mathrm{km})$ of cloud and aerosol at different heights of the lower atmosphere. After Spinhine, number of MPL systems has been successfully deployed in major international field of experiments [Welton et al., 2002; Reid et al., 2003; Baishya et al., 2003; Devi, 2004; Kahn et al., 2007].

There are large numbers of reports showing role of aerosols on modifying microphysics of cloud [Gunn et al., 1957; Squires et al., 1958; Twomey, 1967]. But the application of MPL/PAL (Portable Atmospheric Lidar) systems in retrieving precipitation information is not yet effectively utilized because of smearing of backscatter information by hydrometeors.

The paper describes an indigenous approach for identifying presence of hydrometeors near surface environment leading to precipitating and non-precipitating cloud by adopting a parameter named as Roll off Rate (RoR). The data for this analysis are collected over Gauhati University (GU) by the PAL /MPL system developed for understanding cloud-aerosol interaction over this region.

\section{Observation and Analysis}

The principle of MPL/PAL system is that when a laser beam passes through the atmosphere, the energy interacts with particulates present in the atmosphere reflecting back a fraction of the energy. The MPL or the PAL system operated at GU is capable of receiving backscatter signal from aerosols and clouds up to a height of $5 \mathrm{~km}$ and $15 \mathrm{~km}$ respectively at a resolution of $15 \mathrm{~m}$. The laser transmitter of the PAL generates a pulse of wavelength $\lambda=532 \mathrm{~nm}$, each pulse of width $10 \mathrm{~ns}$, from Nd-YAG laser source and KTP crystal. The backscatter signals from the atmosphere are collected by a telescope of diameter $20 \mathrm{~cm}$ and amplified with a Photo Multiplier Tube (PMT). The output of PMT is processed in LabView environment by software developed by the GU group for obtaining aerosol and cloud features [Baishay, et al., 2003; Devi, 2004; Devi et al., 2008 (a), (b), 2012]. From the bs counts the GU group has synthesized maps of the scattering ambience and therefore the extinction profiles of aerosol and cloud 
after adopting the basic normalization process for conversion of bs count to extinction coefficient. Some representative Lidar echograms showing temporal and spatial variation of normalized bs counts and aerosol $\sigma$ are presented in Figures 1 and 2.

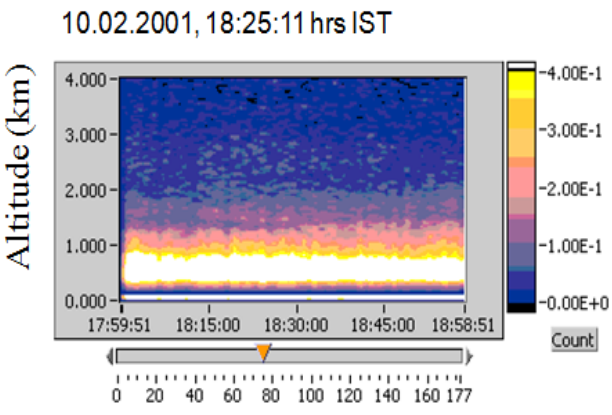

(a)

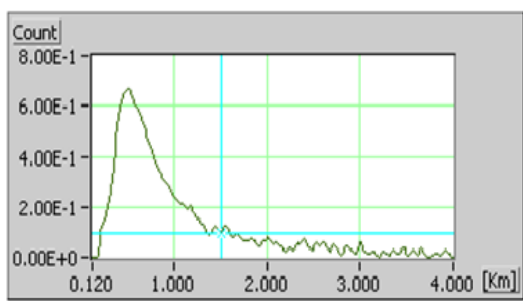

Altitude $(\mathrm{km})$

(b)

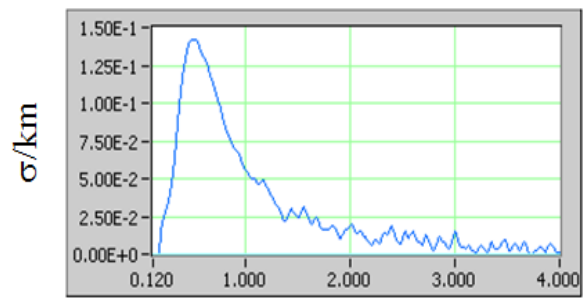

Altitude $(\mathrm{km})$

(c)

Figure 1. (a) Shows Lidar echogram of bs counts covering 1 hour period for a typical vernal equinox month of February (b) Lidar bs count variation with altitude for a particular time of 18:25:11 hrs as marked by arrowhead in fig (a) .(c) Shows aerosol extinction coefficient translated from aerosol count of fig (b)

Figure 1(a) presents a typical Lidar echogram of a vernal equinoxial month. The echogram shows variation of aerosol normalized bs counts with altitudes within an one hour period when relatively strong counts of 0.65 are seen at $800 \mathrm{~m}$ height. The count then starts decreasing to attain a minimum at an altitude of $3.0 \mathrm{~km}$. Similar features are also seen in the altitude variation of bs count and aerosol $\sigma$ profile for the time 18:25:11 hrs (as marked by an arrow head in Figure 1(a)), as presented in the panel (b) and (c). All the profiles of aerosol bs count and $\sigma$ show high value at $800 \mathrm{~m}$ and minimum at $3.5 \mathrm{~km}$. One can however see that aerosol bs count and $\sigma$ profile may undergo drastic modifications with season as presented in Figure 2 for autumnal season.

Non-uniformity in the variation of aerosol bs counts is seen as light traces in echogram of Figure 2 (a) which is also reflected in the figures 2(b). Figure 2(c) shows irregularities in bs counts and of $\sigma$ with altitude for a particular period of 20:1:37 hrs. 


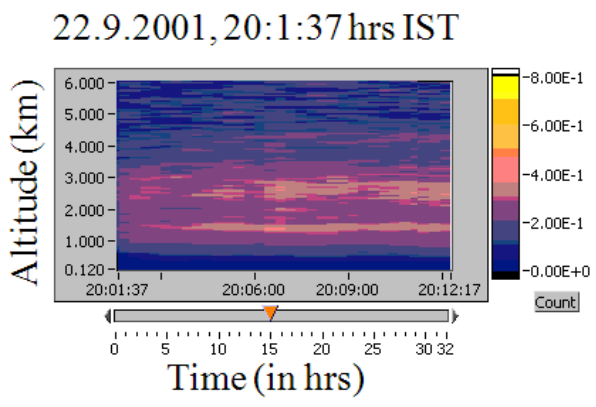

(a)

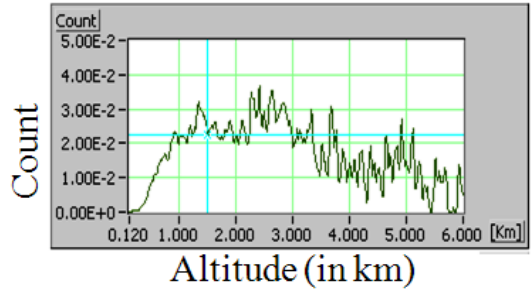

(b)

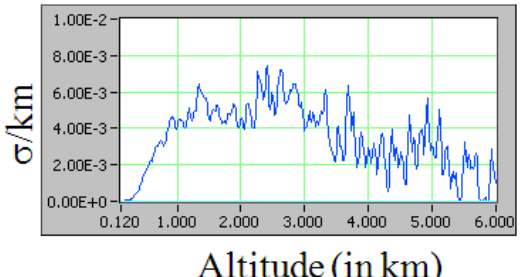

(c)

Figure 2. (a) Shows Lidar echogram of bs counts covering 1 hour period for a typical autumnal equinox month of September (b) Lidar bs count variation with altitude for a particular time of 20:06:00 hrs as marked by arrowhead in fig (a). (c) Shows aerosol extinction coefficient translated from aerosol count of fig (b)

The two representative echograms in Figure 1 and 2 are observed when there are no hydrometeors or growth of cloud in the background. Presence of clouds make strong returns seen as white mark appearing in Figure 3(a) The white signature seen at an altitude of $5 \mathrm{~km}$ is the scattering from the cloud layer that persist for more than an hour. The corresponding bs count and $\sigma$ profile for a particular time 20:11:00 hrs are shown in Figure 3(b) and (c) respectively. In both the bs count and $\sigma$ profiles cloud signature is very distinctly present at an altitude of $5 \mathrm{~km}$. Next we present another echogram (Figure 3 (d)) for a month of April where presence of cloud is observed only for 5 min developed at a height of 3 $\mathrm{km}$. The corresponding bs count and $\sigma$ profile also show the presence of cloud at that height. The two profile of Figure 3(a) and 3(d) are presented here to highlight the basic differences in the shape of the aerosol profile specially at the tail region.

One can note that in the first case (Figure 3(b) and 3(c)) aerosol count and $\sigma$ values show a gradual decrease to reach a minimum before an abrupt increase in their values due to the presence of cloud. But in the second case aerosol bs count as well as $\sigma$ profile show a gradual decrease of the value up to the height of $1 \mathrm{~km}$ and beyond that height both the profiles maintain a constant value till they shows increase in the vicinity of the cloud. This property of aerosol profile might be utilized to identify presence of hydrometeors in the atmosphere. This aspect will be discussed in article 3. 


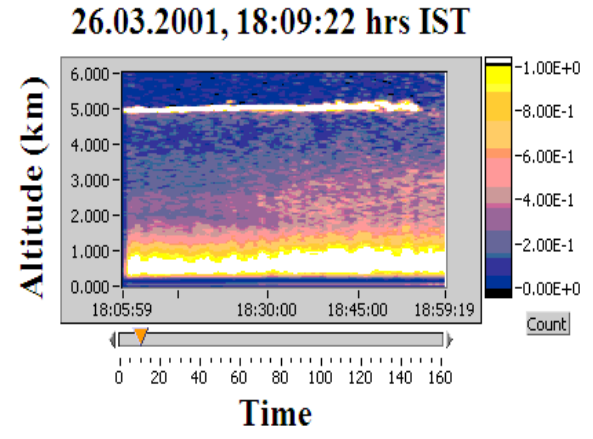

(a)

17.04.2001, 20:11:00 hrs IST

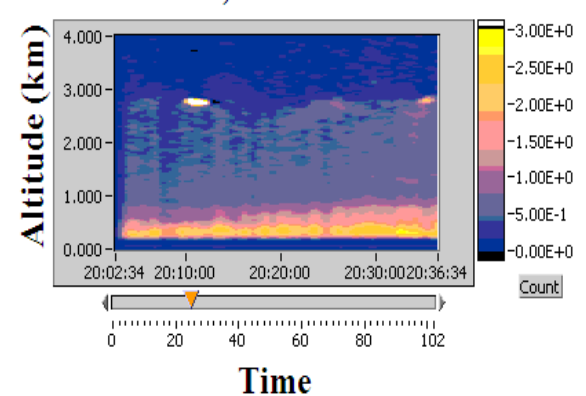

(d)

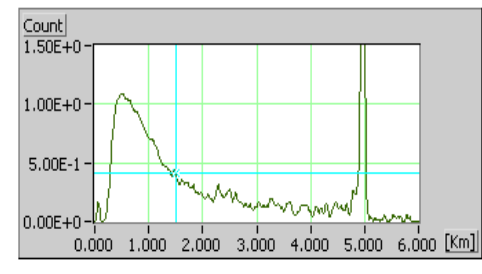

Altitude $(\mathrm{km})$

(b)

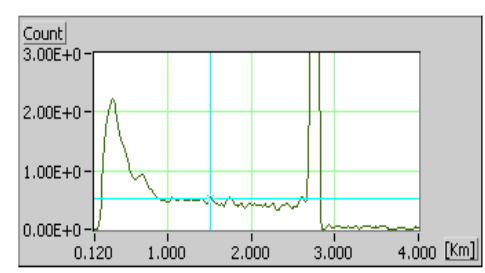

Altitude $(\mathrm{km})$

(e)

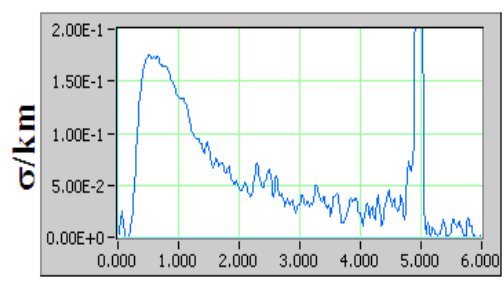

Altitude $(\mathrm{km})$

(c)

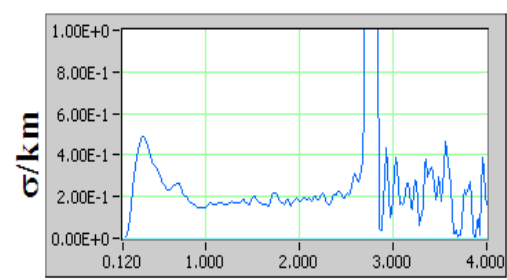

Altitude $(\mathrm{km})$

(f)

Figure 3: (a) \& (d): Lidar echogram in presence of cloud. (b) \& (e) Backscatter count profile for the time marked by the arrowhead in Figure 3(a) \& (d) respectively. (c) \& (f): aerosol extinction coefficient for the time in Figure 3(a) \& (d) respectively.

\section{Approach to determine the cloud type}

For identification of cloud type from aerosol $\sigma$ profile we define a parameter Roll off Rate (RoR) of aerosol $\sigma$ i.e., the rate of decrease of aerosol $\sigma$ from $70 \%$ of its peak value to the point of minimum extinction as dictated by the tail of its profile. Individual $\sigma$ profiles calculated for two years of time are utilized for calculation of RoR. For this analysis $\sigma$ profiles obtained during pre-monsoon and autumnal season of the year are taken into consideration for the convenient rainfall rate of $20-50 \mathrm{~cm}$. The monsoon period is avoided for this analysis because strong monsoon rains. Based on our analysis from a large number of aerosol $\sigma$ profile, two models representing RoR variation are presented: (a) clear air condition (b) in presence of precipitating hydrometeors. These are presented in Figure.4. 


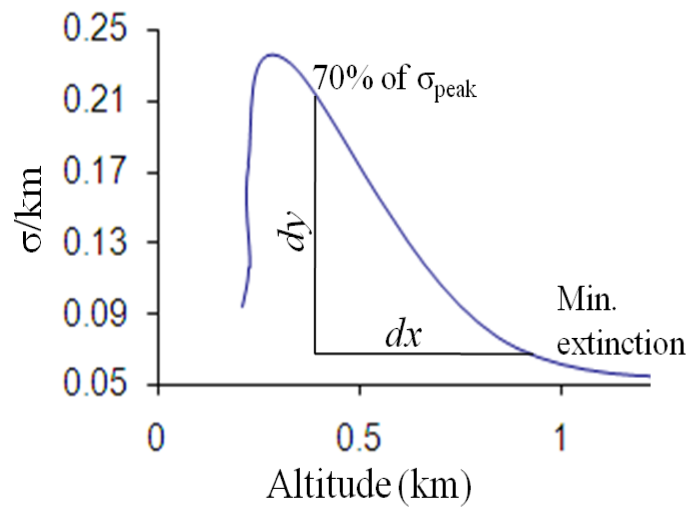

(a)

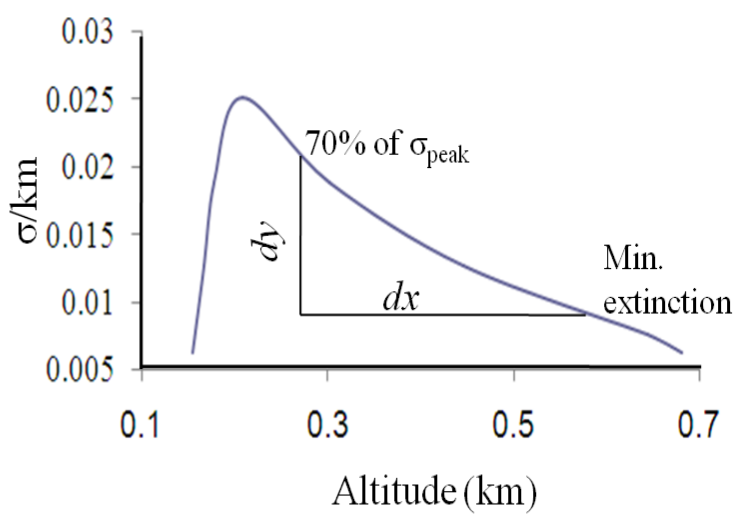

(b)

Figure 4: Displays Model of aerosol extinction profile shape in (a) absence of cloud and (b) presence of cloud

In these figures, $70 \%$ of aerosol $\sigma$ peak is marked as maximum extinction and minimum extinction defined as the $30 \%$ of the corresponding peak value is also identified. Then RoR is defined as $\frac{d y}{d x}$. Now, we examine a large number of aerosol $\sigma$ profiles (a) when cloud level is low and (b) when cloud level is at middle heights.

Figure 5(a) shows Lidar echogram during pre monsoon month (April, 2001) received at 19:02:02 hrs IST to 19:35:02 hrs IST, in presence of cloud at an altitude of 2-2.6 km. Figure 5(b) is bs count profile at 19:20:36 hrs IST shown by arrowhead in Figure 5(a). Similarly, Figure 5(c) is an echogram for autumnal month (November, 2001) with a signature of clouds at a height of $3.8-4.0 \mathrm{~km}$. Figure 5(d) shows the aerosol bs count for a particular time marked by an arrow head of Figure 5(c). One can note that while in Figure 5(b) and 5(d) aerosol bs count decreases gradually to reach its minimum before an abrupt increase in its value caused by presence of a cloud is seen. It is now important to examine the role of precipitating cloud in determination of the shape of the aerosol profile as well as that of the tail region. For this purpose, we place two more aerosol $\sigma$ profiles for two different seasons as representative samples in Figure 6. Here the variations in their tail structure are to be noted. 


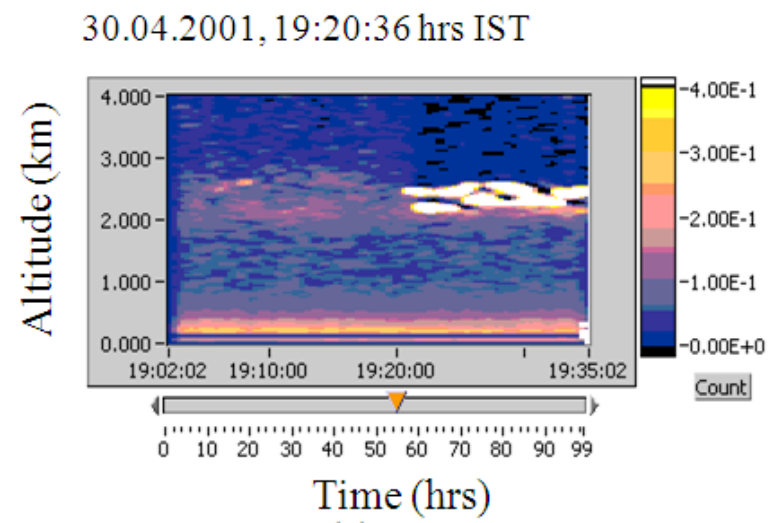

(a)

\subsubsection{1, 18:31:29 hrs IST}

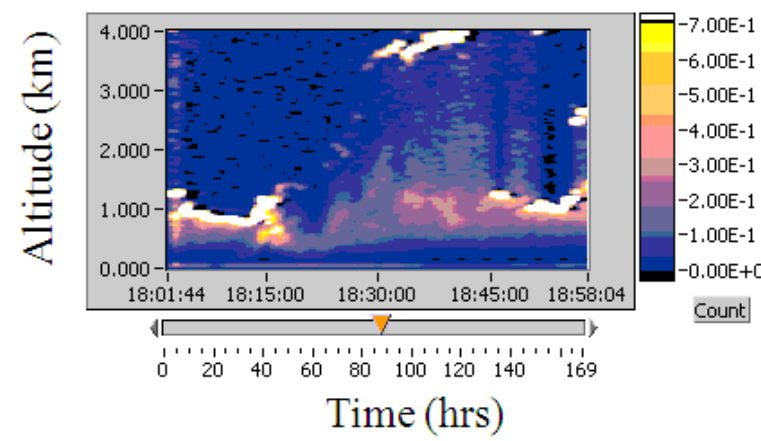

(c)

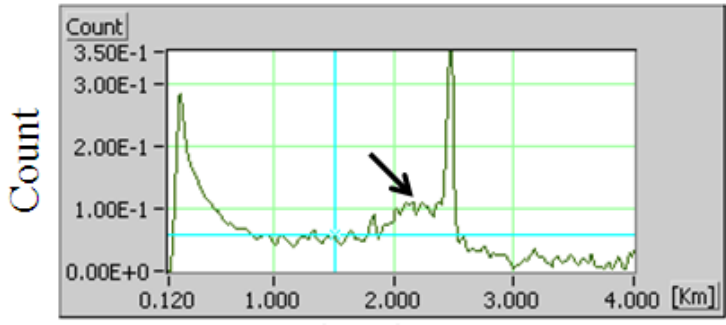

Altitude $(\mathrm{km})$

(b)

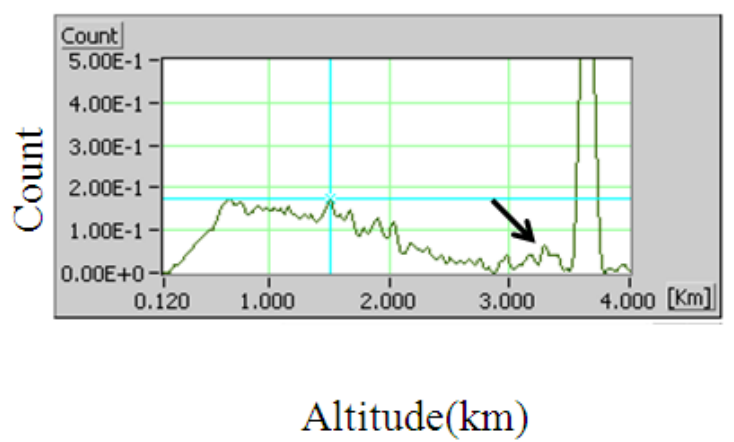

(d)

Figure 5. (a) Lidar echogram for the month of April (30.04.2001), (b) Lidar bs count profile at 19:20:36 hrs IST shown by arrowhead in (a), (c) Lidar echogram for the months of November (07.11.2001), (d) Lidar bs count profile at 18:31:29 hrs IST shown by arrowhead in (c).

Figure 6 shows aerosol $\sigma$ profiles in presence of cloud during vernal equinox and pre-monsoon seasons. Though both the profiles are taken in presence of cloud their variation pattern is different. In Figure 6(a) the extinction coefficient researches maximum at about $500 \mathrm{~m}$ and then decreases sharply to a minimum at $2.5 \mathrm{~km}$ altitude and a cloud signature is present at $3 \mathrm{~km}$. In Figure 6(c) a similar sharp roll off rate is also present. But in Figure 6(b) and (d), we see that after attaining the peak, the decrease of extinction coefficient with height is gradual and it may even show a rise towards the vicinity of the cloud For this purpose rainfall data of these days collected from the TRMM satellite and the local rain 
gauge are presented in Table 1 along with the RoR value. It is seen from the table that RoR values attain low values in presence of rain indicating that RoR can be adopted as a parameter for identifying precipitating and non-precipitating cloud.

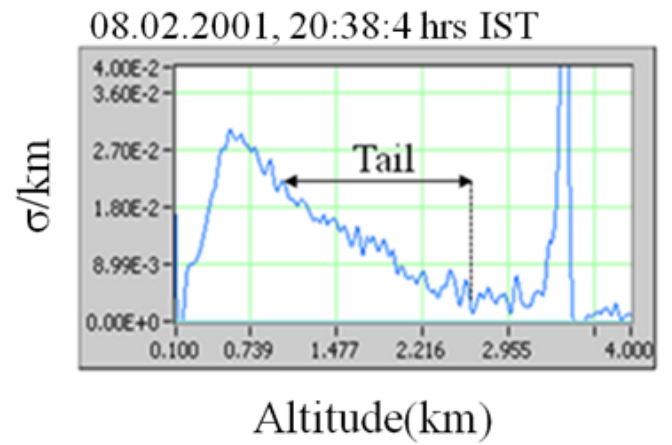

(a)

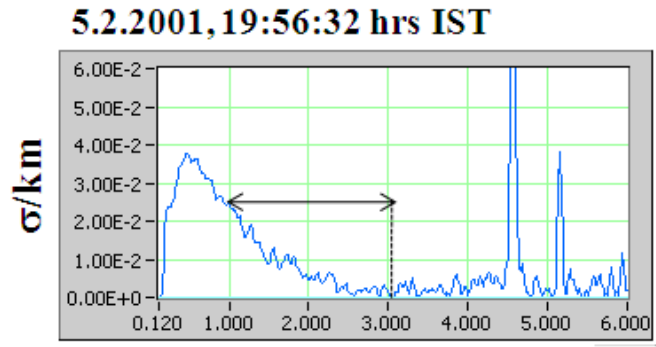

Altitude(km)

(c)

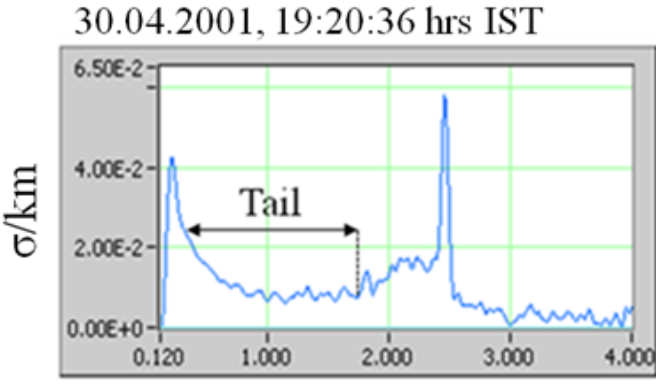

Altitude $(\mathrm{km})$

(b)

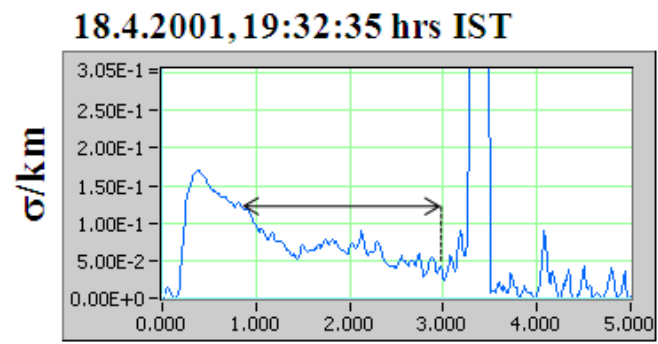

Altitude(km)

(d)

Figure 6: Lidar extinction profile in presence of cloud for (a) \& (c) vernal equinoxial month of February (b) \& (d) pre-monsoon season of April.

Table-I

Association of rainfall magnitude observed by rain gauss \& TRMM with the RoR values obtained from aerosol profile

\begin{tabular}{|c|c|c|c|}
\hline \multirow{2}{*}{ Date } & \multicolumn{2}{|c|}{ Rainfall (mm/hr) } & \multirow{2}{*}{ RoR } \\
\cline { 2 - 3 } & Rain Gauge & TRMM & 0.19 \\
\hline $08 / 02 / 2001$ & No rain & No rain & 0.04 \\
\hline $30 / 04 / 2001$ & 35 & 25 & 0.20 \\
\hline $05 / 02 / 2001$ & No rain & No rain & 0.03 \\
\hline $18 / 04 / 2001$ & 15 & 25 & \\
\hline
\end{tabular}


To examine association between RoR and Rain Rate we calculate the rain rate from the rain gauge data for large number of events and calculate RoR for the corresponding cases. In Figure 7 the association of Rain rate and RoR is presented.

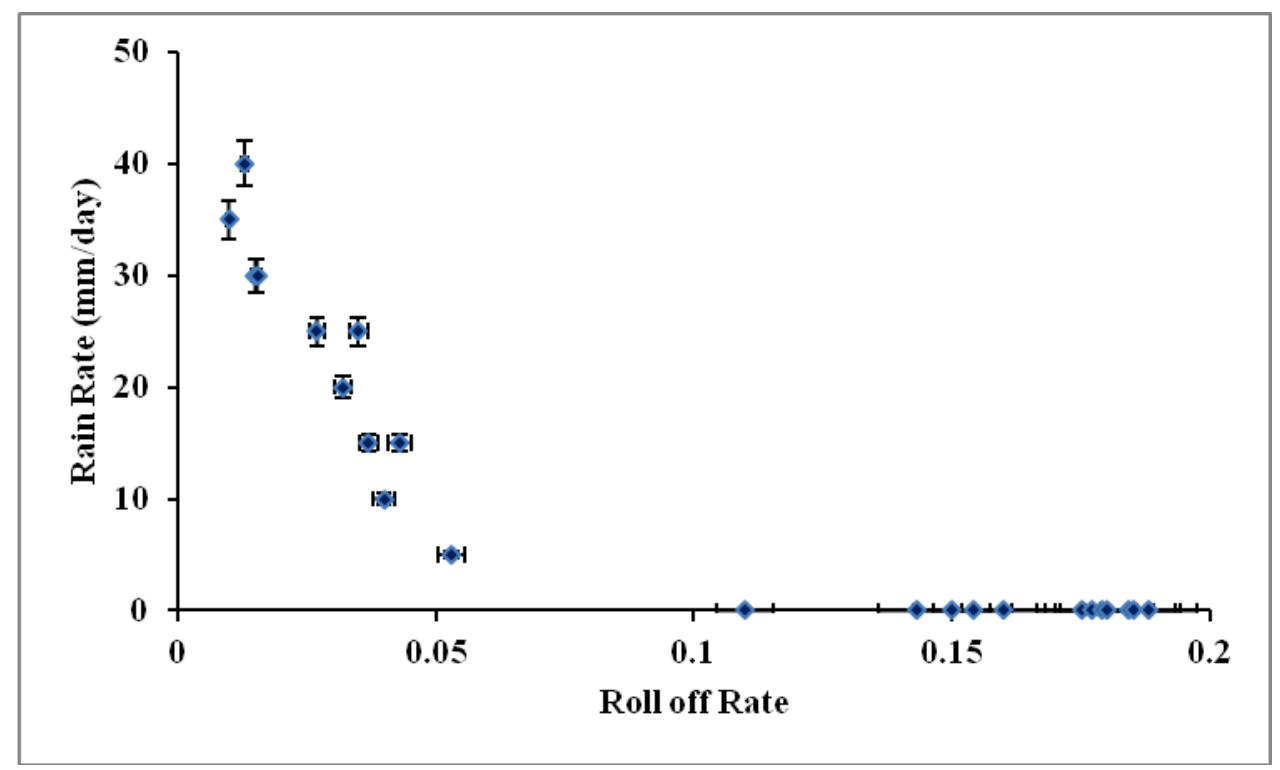

Figure 7. Displays relation between rain rate and RoR . One can note that with increase of RoR, precipitation disappear

From the relation between RoR and rain rate $(\mathrm{mm} / \mathrm{hr})$ it is found that the typical value of RoR when precipitating cloud is present, lies between 0.01-0.050 and in presence of non-precipitating cloud this figure is higher and it varies from 0.17-0.19. For higher values of RoR exceeding 0.08 , the rain rate goes down almost to zero. As RoR value depends on type of cloud, the low RoR situation indicates formation of precipitating cloud and this can be explained by aerosol swelling in the high relative humidity (RH) environment. Figure 8 is an example of change in optical properties of aerosols with time in the vicinity of cloud. 


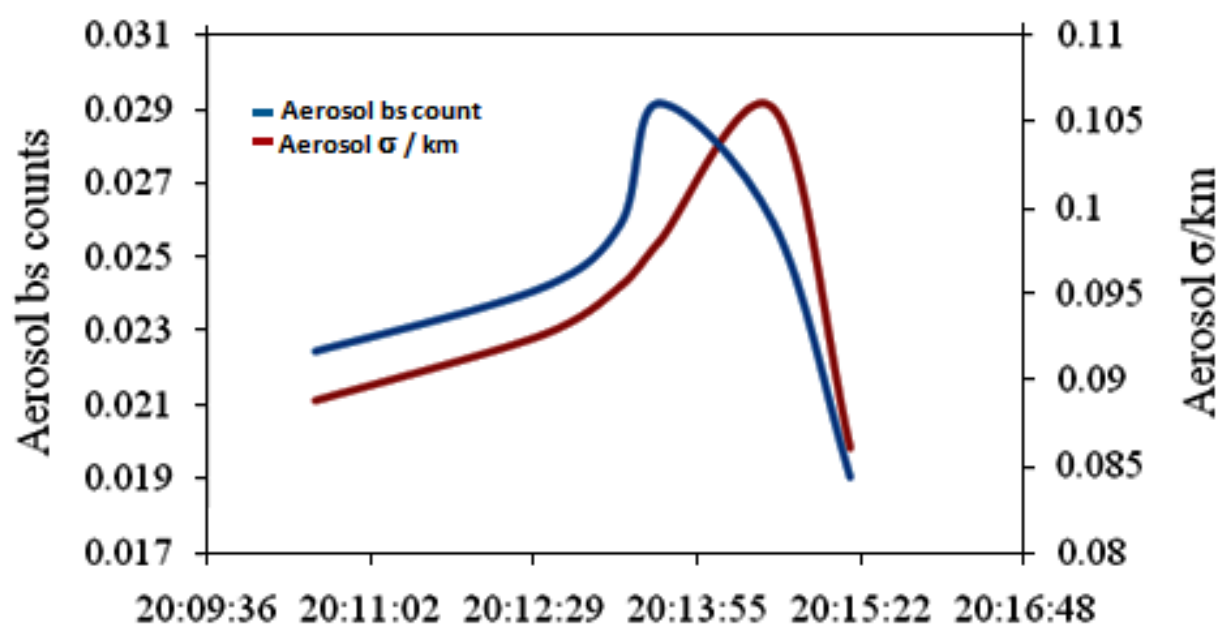

Time

Figure 8: Change in aerosol bs count and extinction coefficient with time at the vicinity of a cloud during pre monsoon season

\section{Discussion and Conclusion}

The effects of aerosol on growth and development of precipitation are reported by many workers around the globe [Campbell et al., 1998; Stokes and Schwartz, 1994]. Aerosol-cloud features in association with surface rain also been reported by [Devi et. al, 2014], by using MPL echogram. Relation between the cloud base and hydrometeors information are also presented by many other workers [Clothiaux et al., 1998]. However PAL/ MPL system cannot give role of aerosol in cloud seeding [Kriger, 2002]. But in this paper an indigenous approaches presented to identify presence of hydrometeors in the environment by analysis the decay rate of aerosol especially in the vicinity of growth of a cloud. The reliability of the approaches, i.e. the utilization of the parameter RoR in identifying a precipitating cloud and hence the rain magnitude is found to be reliable in $70 \%$ of the cases. However the limitation of the approaches is that the method cannot be utilized for obtaining rain magnitude during monsoon time in severe precipitation condition. 


\section{Reference}

Baishay, R., Devi, M., Barbara, A. K. Software for lidar data analysis: development of application on MPL setup. Ind. J. Radio \& Space phys. 32, 114-117, 2003.

Bhavani Kumar, Y. Development of Lidar Techniques for environmental Remote sensing. Int. J. of Eng. Sci. and technol. 2, 5872-5881, 2010.

Campbell, J.R., Dennis, L.H., Spinhirne, J.D., Scott,III, V.S., Turner, D.D. Operational processing and cloud boundary detection from Micro Pulse Lidar data, in: Singh, U.N., Ismail S. and Schwemmer, G.K. (Eds.), Proceedings of 19th ILRC. 119-210,1998.

Campbell, J. R., Hlavka, D. L., Welton, E. J., Flynn, C. J., Turner, D. D., Spinhirne, J. D., Scott III, V. S., and Hwang, I. H. Fulltime eye-safe cloud and aerosol lidar observation at atmospheric radiation measurement program sites: Instruments and data processing, J. Atmos. Oceanic Tech. 19, 431-442, 2002.

Clothiaux, E.E., Mace, G.G., Ackerman, T.P., Kane, T.J., Spinhirne, J.D, Scott, V.S. An automated algorithm for detection of hydrometeor returns in micro pulse lidar data. J Atmos and Ocean Techn, 15, 1035-1042,1998.

Devara, P. C. S. and Raj, P. E. A bistatic lidar for aerosol studies. Inst. Electron. Telecommum. Engrs. Tech. Rev. 4, 412-415, 1987.

Devara, P. C. S., Maheskumar, R. S., Raj, P. E., Pandithurai, G., and Dani, K. K. Recent trends in aerosol climatology and air pollution as inferred from multi-year lidar observations over a tropical urban station. Int. J. Climatol. 22, 435-449, 2002.

Devi, M. and Barbara, A. K. Development of a Portable Lidar. Report No Phys. elec/lidar/X financed by MIT, Delhi. 1- 83, 2004.

Devi, M., Barbara, A. K. and Saikia, M. Studies on transmission, reception and detection analysis in incoherent differential absorption lidar. Report No Phys.elec/DIAL/v financed by LASTEC, DRDO, New Delhi. 1-27, 2008(a).

Devi, M., Barbara, A. K., Saikia, M. and Chen, W. Vertical distribution of optical parameters of aerosols using Portable Atmospheric Lidar system of Gauhati University. Ind. J. Rad. \& Space Phys. 37, 333340, 2008(b).

Devi, M., Barbara, A. K., Saikia, M., Choudhury, B. and Sarmah, H. Micro pulse Lidar: a tool for analyzing interactive relation between aerosol and cloud formation. Int. J. Engg. Sc. \& Mgmt. II, 2012. 
M. Devi, A. K. Barbara and A. Depueva. Micropulse lidar observation at Gauhati University for understanding atmospheric dynamics on aerosol -cloud interaction \& precipitation International Journal of Electronics and Applied Research (IJEAR) 1, 55-67, 2014.

Gunn, R. and Phillips, B. B. An Experimental Investigation of the Effect of Air Pollution On the Initiation of Rain. Journal of Meteorology. 14, 272-280, 1957.

Jayaraman, A., Ramachandran, S., Acharya, Y. B. and Subbaraya, B. H. Pinatubo volcanic aerosol layer decay observed at Ahmedabad (23 N) India using Nd:YAG backscatter lidar. J. Geophys. Res. 100, 23 209-23 214, 1995.

Kahn, R., Li, W., Moroney, C., Diner, D., Martonchik, J. and Fishbein, E. Aerosol source plume physical characteristics from space-based multiangle imaging. J. Geophys. Res. 112 D, 11205, 2007.

Kriger, O .The indirect aerosol effect over Europe. Geophysical Research Letter, 29, 31-1-31-4 , 2002.

McCormick, M. P., Winker, D. M., Browell, E. V., Coakley, J. A., Gardner, C. S., Hoff, R. M., Kent, G. S., Melfi, S. H., Menzies, T. T., Platt, C. M. R., Randall, D. A. and Reagan, R.A. Scientific investigations planned for the Lidar In-Space Technology Experiment (LITE). Bull. Am. Meteorol. Soc. 74, 205-214, 1993.

Reid, J., Kinney, J. and Wesphal, D., et al. Analysis of measurements of Saharan dust by airborne and ground based remote sensing methods during the Puerto Rico Dust Experiment (PRIDE). J. Geophys. Res. 108, 8586, 2003.

Spinhirne, J. D. Micro Pulse Lidar. Trans. Geosci. Remote Sens. 13, 48-55, 1993.

Squires, P. The microstructure and colloidal stability of warm clouds. Tellus. 10, 256-271, 1958.

Stokes, G. M. and Schwartz, S. E. The Atmospheric Radiation Measurement (ARM) Program: Programmatic background and design of the Cloud and Radiation Test Bed. Bull. Amer. Meteor. Soc., 75, 1201-1222, 1994.

Welton, E. J., Voss, K. J., Quinn, P. K., Flatau, P., Markowicz, K., Campbell, J., Spinhirne, J. D., Gordon, H. R. and Johnson, J. Measurements of aerosol vertical profiles and optical properties during INDOEX 1999 using micropulse lidars. J. Geophys. Res., 107(D1), 8019, 2002. 